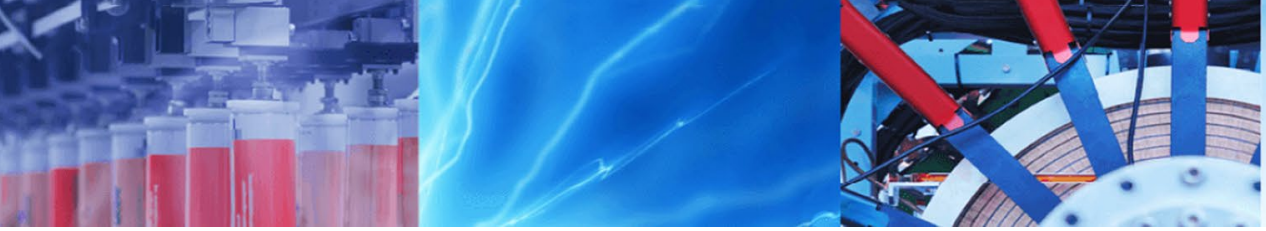

Research Article

\title{
Tamarindus Indica fruit shell ash: a low cost and effective catalyst for biodiesel production from Parinari curatellifolia seeds oil
}

\author{
Christian S. Nabora ${ }^{1,2} \cdot$ Cecil K. Kingondu ${ }^{3,4} \cdot$ Thomas T. Kivevele $^{1}$
}

(c) Springer Nature Switzerland AG 2019

\begin{abstract}
The study evaluated the potential use of agricultural waste, Tamarindus indica fruit shell ash, as a solid base catalyst for production of biodiesel. The catalyst was prepared by calcination of $T$. indica fruit shell at $800^{\circ} \mathrm{C}$ in muffle furnace for $3 \mathrm{~h}$. Branauer-Emmett-Teller, thermal gravimetric analysis, X-ray diffraction, scanning electron microscope, X-ray florescence, and Hammett indicator techniques were used to characterize the physicochemical properties of the produced catalyst. The catalyst had basic strength of greater than 9.7 and mesoporous structure with pore size $\mathrm{d}=3.2 \mathrm{~nm}$. The crystalline phase was made up of calcium oxide, potassium oxide, and magnesium oxide. The catalyst was tested for biodiesel production using Parinari curatellifolia seeds oil. The results showed that the best operating parameters for the production of biodiesel were 9:1 methanol to oil molar ratio, $125 \mathrm{mg}$ catalyst ( $5 \mathrm{wt} \%$ of oil), $2 \mathrm{~h}$ reaction time, and $60^{\circ} \mathrm{C}$ reaction temperature. These optimized operating parameters afforded a maximum yield of $96.2 \%$. Also, fuel properties of biodiesel: acid value, viscosity, and flash, pour, and cloud points were investigated and compared to the ASTM standards limits D6751. The results were observed to be in good agreement with the ASTM standards limits for biodiesel. In addition, the catalyst was easily separated and subsequently reused for four runs in biodiesel production. Thus, Tamarind fruit shell derived catalyst is very promising for the production of biodiesel due to its high performance, low-cost, easy preparation and availability.
\end{abstract}

Keywords Tamarindus indica fruit shell $\cdot$ Biodiesel $\cdot$ Solid base catalyst $\cdot$ Parinari curatellifolia $\cdot$ Transesterification

\section{Introduction}

Energy is a key component for economic development, poverty reduction, and prosperity [1]. Diesel and petrol are the most commonly used fossil fuels in the energy mix contributing more than $82 \%$ of the world's total primary energy. Fossil fuels are a precious resource with limited supply but their by-products affect people and the environment [2]. The use of renewable and clean energy obtained from replenishable sources such as biomass offers solutions for various fossil fuel-linked problems that challenge many societies around the world. Biofuels including biodiesel, have become more attractive due to the fact that biomass feedstocks are easily available, cheap, easily bio-degraded, and their combustion byproducts are less harmful and are environment friendly [3]. Biodiesel is a mixture of alkyl esters obtained when tryglycerides are transesterified in the presence of catalyst giving glycerol as by-product [4].

The conventional production of biodiesel using homogeneous catalysts has been replaced by eco-friendly heterogeneous catalysts [5]. These heterogeneous basic catalysts are advantageous in nature since they are easily separated from reaction mixture, recyclable (cost

$\triangle$ Christian S. Nabora, naborac@nm-aist.ac.tz; naborachristian@gmail.com; Cecil K. Kingondu, kingonduc@biust.ac.bw | ${ }^{1}$ Department of Materials and Energy Science and Engineering (MESE), Nelson Mandela African Institution of Science and Technology (NM-AIST), PO Box 447, Arusha, Tanzania. ${ }^{2}$ Department of Transport Engineering and Technology, National Institute of Transport, PO Box 705, Dar es Salaam, Tanzania. ${ }^{3}$ Department of Chemical and Forensic Sciences, Botswana International University of Science and Technology, Private Bag 16, Palapye, Botswana. ${ }^{4}$ Department of Chemistry, South Eastern Kenya University, PO Box 17090200, Kitui, Kenya. 
effective), tolerant to moisture and high free fatty acid (FFA), non-corrosive and can be derived from abundant renewable resources [6-10]. Various researchers have investigated the potential of agricultural wastes and unutilized biomass as sources of solid catalysts for biodiesel production. Good examples of biomass derived catalysts are calcined shells: egg shells [3, 11], snail shells [12], sea shells [13], fish scales [5], animal bones [14, 15] and agricultural wastes such as coconut wastes [16], cocoa pod, rice husk [17], and camphor tree ash impregnated with $\mathrm{K}_{2} \mathrm{CO}_{3}$ [18].

Generally, biomass in nature has variable amounts of inorganic constituents. The major inorganic constituents in biomass are $\mathrm{Ca}, \mathrm{Mn}, \mathrm{Fe}, \mathrm{Ti}, \mathrm{Si}, \mathrm{Al}, \mathrm{Cl}, \mathrm{S}, \mathrm{Mg}, \mathrm{P}, \mathrm{Na}$, and other trace elements $[19,20]$. Biomass with high amount of carbonate can be transformed into their corresponding oxides through thermal treatment (calcination process) $[21,22]$. According to Abdullah et al. [10], calcination of the biomass can be done from 300 to $1000^{\circ} \mathrm{C}$ depending on the type of biomass. In their study they observed that, biomass residue with high quantities of $\mathrm{Ca}(>40 \mathrm{wt} \%)$ upon calcination generates $\mathrm{CaO}$ that is potentially active as heterogeneous catalyst for biodiesel production. Furthermore, Vassilev et al. [20] noted that biomass ashes calcined at $500^{\circ} \mathrm{C}$ and above, have high crystalline character and limited amorphous inorganic and organic materials and thus high activity in biodiesel production.

Tamarindus indica fruit shells (TIFSs) are among agricultural wastes from juice processing industry that are naturally rich in calcium compounds [23]. It comes from Tamarindus indica tree plant which belongs to the dicotyledonous family: Caesalpiniaceae, indigenous to tropical Africa. The pulp is used in preparing different foods such as confections, curries, sauces, juices and other beverages leaving shells with no value. Also, tamarind drinks are already in the market in many countries making Tamarind fruit shell ubiquitous [24]. Tamarind fruit shell wastes are cheap and made up of $\mathrm{CaCO}_{3}(11.1 \%)$ by weight [25]. Also, elements such as K (13.08), Ca (36.6) Mn (12.1), Mg (10.4), $\mathrm{Na}$ (8.90), $\mathrm{Zn}$ (7.0), $\mathrm{Fe} \mathrm{(4.5)} \mathrm{and} \mathrm{Cu}(2.10) \mathrm{mg} / 100 \mathrm{~g}$ of dry matter are known to be present [26]. TIFSs have high amounts of alkaline earth metals. Like any other biomass wastes, when burned to ashes, they readily form metal oxides that can be used as solid catalysts for transesterification process [27].

Thus, in this study, a new catalyst from Tamarindus indica fruit shell was developed, characterized and its performance in production of biodiesel from Parinari curatellifolia seeds oil (PCSO) tested. P. curatellifolia seeds are not commonly used as foodstuff and have high oil content of about 38.5\% [28-30]. However, PCSO has not extensively been studied for biodiesel production. P. curatellifolia is an African tropical evergreen fruit tree with a mushroom like shape, belonging to the family Chrysobalanceae, found in many African forests. In Tanzania, the plant grows well in the northern and southern highlands such as Iringa where it is locally known as msawula in Njombe whilst in Mbeya is known as mbende [31]. The use of ashes from agricultural residues can serve as cheap, effective and potential catalyst for a number of reactions including transesterification [17, 32]. Most of biomass based catalysts exhibit good catalytic performance evinced by high biodiesel yield of more than $80 \%$ at optimal conditions $[22,33]$.

\section{Materials and methods}

\subsection{Materials and reagents}

TIFSs were collected from juice processing industry and market places in Arusha Tanzania. The ripen Parinari fruits were collected from fields in Njombe region in the Southern highlands of Tanzania. The reagents methanol (99.8\%), ethanol (absolute), isopropyl alcohol (95\%), sodium hydroxide $(\mathrm{NaOH})$, potassium hydroxide $(\mathrm{KOH})$ were from LOBA Chemie. Phenolphthalein indicator (GRIFFChem), $\mathrm{HCl}$ (37\%) from BDH Chemicals, Wijs (iodine monochloride) reagent, benzene and benzoic acid were from Sigma Aldrich. All chemicals were of analytical grade and thus no purification was done.

\subsection{Catalyst preparation and characterization}

The TIFSs were thoroughly washed with tap water and rinsed with distilled water to remove dirt and other particulate materials. The cleaned TIFSs were oven dried at $105^{\circ} \mathrm{C}$ for $12 \mathrm{~h}$ and ground for calcination. Before calcinations TGA analysis was done using Linseins thermal analysis machine (STA 1000). The weight of the sample used was $4.33 \mathrm{mg}$ and heating temperature range from 29.6 to $900^{\circ} \mathrm{C}$ at a ramp rate of $5^{\circ} \mathrm{C} \mathrm{min}^{-1}$ was used. The ground catalyst precursor was calcined in a muffle furnace at $800{ }^{\circ} \mathrm{C}$ for $3 \mathrm{~h}$ at a ramp rate of $5^{\circ} \mathrm{C} \mathrm{min}^{-1}$ to form Tamarindus indicia fruit shell ash (TIFSA). The resultant TIFSA was collected, cooled in desiccator for further analysis and used as heterogeneous base catalyst for trans-esterification of $P$. curatellifolia seeds oil.

Elemental analysis was done using SPECTRO XEPOS machine fitted with energy dispersive $X$-rays florescence spectrometer (EDXRF). The microstructure of as-prepared catalysts was analyzed using a field emission scanning electron microscope (SEM-JSM-7600F Thermo NORAN System7) fitted with EDX. The textural parameters of the catalyst were evaluated using Quanta chrome Nova 4200 with nitrogen adsorption-desorption isotherms acquired at $77.3 \mathrm{~K}$. The catalyst was degassed at $200{ }^{\circ} \mathrm{C}$ prior to the sorption analysis. Surface area was determined using BET equation. 
Barrett-Joyner-Halenda (BJH) method was used to calculate pores size distribution from the desorption isotherm. The $\mathrm{X}$-ray diffraction patterns were acquired using $\mathrm{X}$-ray power diffractometer (XRD, MAC MXP18Tokyo, Japan), with Cu-Ka radiation. The basic strength of the catalyst was determined using Hammett indicator method using phenolphthalein to give qualitative information of the catalyst.

\subsection{Physical and chemical properties of $P$. curatellifolia seeds oil}

The physical-chemical properties of crude $P$. curatellifolia seeds oil; saponification, acid, and iodine values as well as oil content oil content were determined using American Standard Testing Method (ASTM, 1983) and American Oil Chemists Society (AOCS) Official Methods [34, 35].

\subsection{Biodiesel production}

The production of biodiesel was done using batch reactor. The reactor was fitted with water bath, heating plate with magnetic stirrer, $250 \mathrm{~mL}$ Erlenmeyer flat bottomed flask fitted with reflux condenser and thermometers. P. curatellifolia seeds oil was measured and preheated at $105^{\circ} \mathrm{C}$ for $5 \mathrm{~min}$ to reduce water content and allowed to cool to $65^{\circ} \mathrm{C}$. In order to determine the optimal yield and conditions for the biodiesel production, various reaction parameters such as reaction time, methanol to oil molar ratio and amount of catalyst loading was varied. During transesterification process, catalyst loading was varied from 1 to $6 \mathrm{wt} \%$ of oil at intervals of 1\%; methanol to oil molar ratios of 3:1, 6:1, 9:1, and 12:1 were used and the reaction time was also altered from 1 to $4 \mathrm{~h}$ at intervals of $30 \mathrm{~min}$. The reaction temperature was maintained at $60^{\circ} \mathrm{C}$ below boiling point of methanol while stirring at $3000 \mathrm{rpm}$ using magnetic stirrer. After the reaction, the mixture was let to cool and two distinct layers of catalyst at bottom and the mixture of glycerol and biodiesel at the top were formed. The top mixture was separated and put into a separating funnel where it was kept overnight without agitation. Two more distinct layers were formed, bottom layer being glycerol and the top layer biodiesel. The raw biodiesel was separated from glycerol purified using vacuum distillation flask followed by partial heating at $70{ }^{\circ} \mathrm{C}$ to remove excess methanol. The biodiesel was then washed four times with warm deionized water to remove traces of impurities such soap, glycerol, and catalyst. The washed biodiesel was dried by using anhydrous $\mathrm{MgSO}_{4}$ overnight to remove the residual water content. Then, the yield was calculated using Eq. (1)

$\%$ yield $=\frac{\text { weight of biodiesel }}{\text { weight of oil }}$

\subsection{Characterization of biodiesel properties}

The biodiesel produced from $P$. curatellifolia seeds oil using TIFSA based catalyst was tested and analyzed for both physical and chemical properties at Tanzania Bureau of Standards (TBS). Physical and chemical properties of the samples were analyzed according to the standard test methods: density and kinematic viscosity was measured by Anton Parar Stabinger viscometer using ASTM D7042 testing method, cloud point and pour point were tested using cloud and pour point test cabinet as per ASTM D2500 and ASTM D97 test method, respectively. Flash point was determined by Pensky-Martin open cup tester using test method ASTM D93 while American Oil Chemists Society (AOCS) Official Method CD1-25 and AOCS Official Method CD3-25 were used to determine acid, iodine and saponification values.

\subsection{Catalyst reusability}

One of the benefits of heterogeneous over homogeneous catalyst is its reusability. In this study, the reusability of the synthesized catalyst was examined. The catalyst spent in the 1st biodiesel production run was washed with methanol severally to remove oil and glycerol content. The catalyst was then oven dried at $110^{\circ} \mathrm{C}$ for $2 \mathrm{~h}$ to remove methanol and any traces of water formed during the transesterification reaction process. The dried spent catalyst was then cooled inside a desiccator and used for biodiesel production in the subsequent run. This process was repeated four times and the yield of biodiesel of each in subsequent run calculated using Eq. (1).

\section{Results and discussion}

\subsection{Catalyst characterization}

The appropriate calcination temperatures for catalyst precursor TIFSs in this study was obtained through thermogravimetric analysis as depicted in Fig. 1. Upon calcination, significant mass loss of $75 \%$ was observed at temperature between 250 and $480^{\circ} \mathrm{C}$ where volatile matter escaped from the catalyst precursor materials. Thermal stability of the catalyst materials at temperature from 500 to $750{ }^{\circ} \mathrm{C}$ was an indication that the decomposition of the catalyst precursor was complete with metal oxides remaining as the residue. Since TIFSs have high content of $\mathrm{CaCO}_{3}$, temperature higher than $750{ }^{\circ} \mathrm{C}$ was therefore used to decompose all the carbonate based materials to $\mathrm{CaO}[3$, 36 ,37]. According to Abdullah et al. [10], depending on the biomass type, carbonates of calcium and potassium dissociate between 700 and $900^{\circ} \mathrm{C}$ to form their respective 


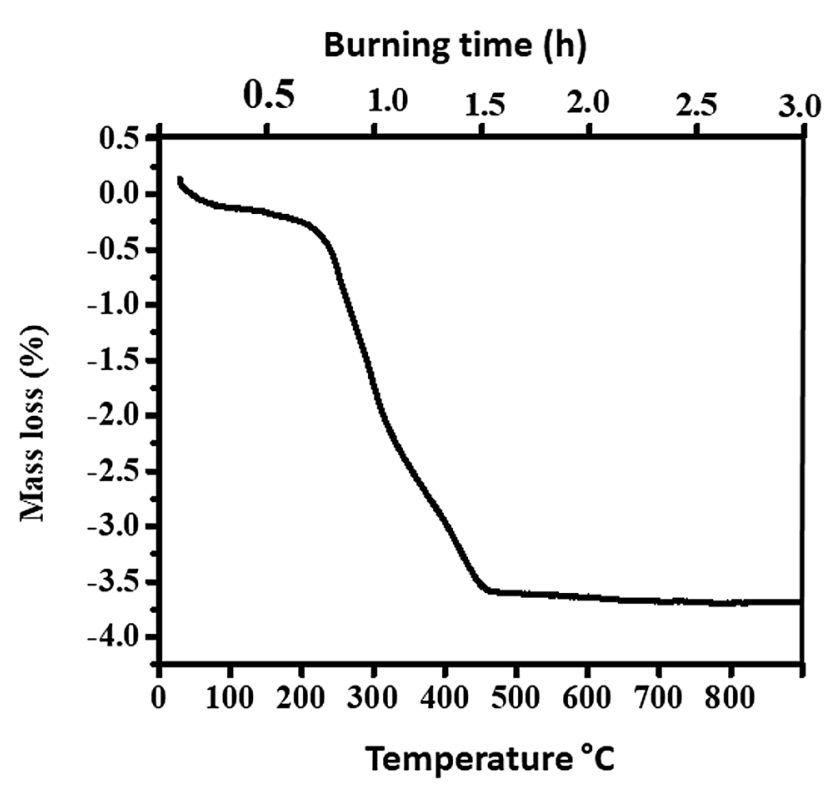

Fig. 1 TGA profile of catalyst precursor TIFSs at the temperature range between 30 and $900^{\circ} \mathrm{C}$

metal oxides while releasing $\mathrm{CO}_{2}, \mathrm{H}_{2} \mathrm{O}$, and other organic materials when burnt in air. The high content of calcium oxide was confirmed by the XRF analysis of the ash: ca $47.4 \% \mathrm{CaO}$.

Furthermore, to determine the catalyst basic strength, Hammett indicator method was used with phenolphthalein as the indicator. The catalyst $(25 \mathrm{mg}$ ) was tested with $0.5 \mathrm{~mL}$ of Hammett indicator solution and color change was noted. The color of the mixture was observed to change to pink implying that the catalyst had stronger basic property, that is, $\mathrm{H}>9.8$. $[2,38]$. The chemical composition of TIFSA calcine at $800^{\circ} \mathrm{C}$ was obtained by XRF technique. The sample was mainly composed of $\mathrm{CaO}$ (47.4\%), $\mathrm{K}_{2} \mathrm{O}(19.2 \%), \mathrm{MgO}(5.1 \%), \mathrm{SiO}_{2}(3 \%), \mathrm{P}_{2} \mathrm{O}_{5}(3.1 \%)$, and traces of other compounds. The presence of significant amount of alkaline and alkaline earth metal oxides, $\mathrm{CaO}, \mathrm{K}_{2} \mathrm{O}$, and $\mathrm{MgO}$ in the prepared catalyst explains its good performance as a base catalyst in biodiesel production $[27,37,38]$.

The XRD pattern of the TIFSA catalyst calcined at $800^{\circ} \mathrm{C}$ is shown in Fig. 2 . The pattern was obtained using CuKa radiation with wavelength $(\lambda)$ of $1.5418 \mathrm{~nm}$ from 5 to 90,2 theta degrees. The diffraction peaks at 20:32.18, $37.52,53.95,63.75,67.39,79.55$, and 88.31 degrees correspond to $\mathrm{CaO}$ based on Joint Committee on Powder Diffraction Standards (JCPDS) card file number 00-0371497. In addition, the XRD pattern of the TIFSA catalyst was similar to $\mathrm{CaO}$ patterns reported in the literature $[3,11,39]$. The high intensity of the peaks and narrow peak widths are indicative of good crystallinity of the materials. The unmarked peaks in the XRD pattern are

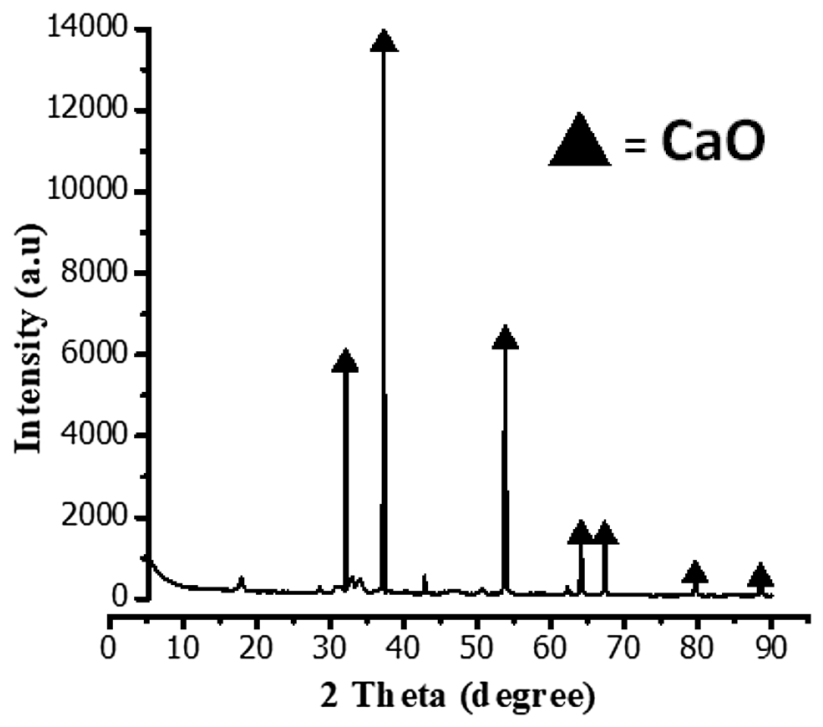

Fig. 2 XRD pattern of TIFSs derived catalyst calcined at $800^{\circ} \mathrm{C}$

attributed to $\mathrm{CaCO}_{3}$ phase and other impurity phases of the trace elements in the TIFSs.

Figure 3 presents SEM images of the TIFSA catalyst and the chemical composition of the ash as determined by EDS. The SEM micrographs in Fig. 3a-c indicate that, TIFSA had pseudo spherical microstructure constructed of particles of irregular morphology. The interparticle porosity clearly seen in the micrographs, Fig. 3a-c, are very good for mass transport during transesterification reaction and for exposing the active sites and thus the good performance of the catalyst. Figure $3 \mathrm{~d}$ shows the elemental composition of TIFSA as determined by EDS. It was observed that Ca was present at substantially higher amount compared to $\mathrm{K}$ and $\mathrm{Si}$. This suggested that $\mathrm{CaO}$ was the major compound. The aluminum (AI) detected in the sample was probably coming from the $\mathrm{Al}$ sample holder since Al was not detected in the sample by XRF. The results were in good agreement with that determined by XRF, however, $\mathrm{Mg}$ and thus $\mathrm{MgO}$ was not observed by EDS technique.

The BET method was employed to determine the specific surface area of TIFSA calcined at $800^{\circ} \mathrm{C}$. The surface area was found to be $378 \mathrm{~m}^{2} \mathrm{~g}^{-1}$ and total pore volume of $0.585 \mathrm{~cm}^{3} / \mathrm{g}$ was obtained computed from the adsorption isotherm at relative pressure $(\mathrm{P} / \mathrm{Po})$ of less or equal to 1 . In this study, the Barret-Joyner-Halenda method (BJH) was used to calculate the pore size distributions over the entire surface of the catalyst. The pore diameter was found to be $3.2 \mathrm{~nm}$, characteristic of a mesopore catalyst. According to Zabeti et al. [27], the specific surface area and pores volume together play a major role in the activity and hence the performance a catalyst. The prepared catalyst showed high surface area and small 
Fig. 3 SEM images of the TIFSA calcined at $800^{\circ} \mathrm{C}$ a low magnification image of the catalyst, b, c high magnification images of the catalyst, $\mathbf{d}$ elemental analysis by EDS
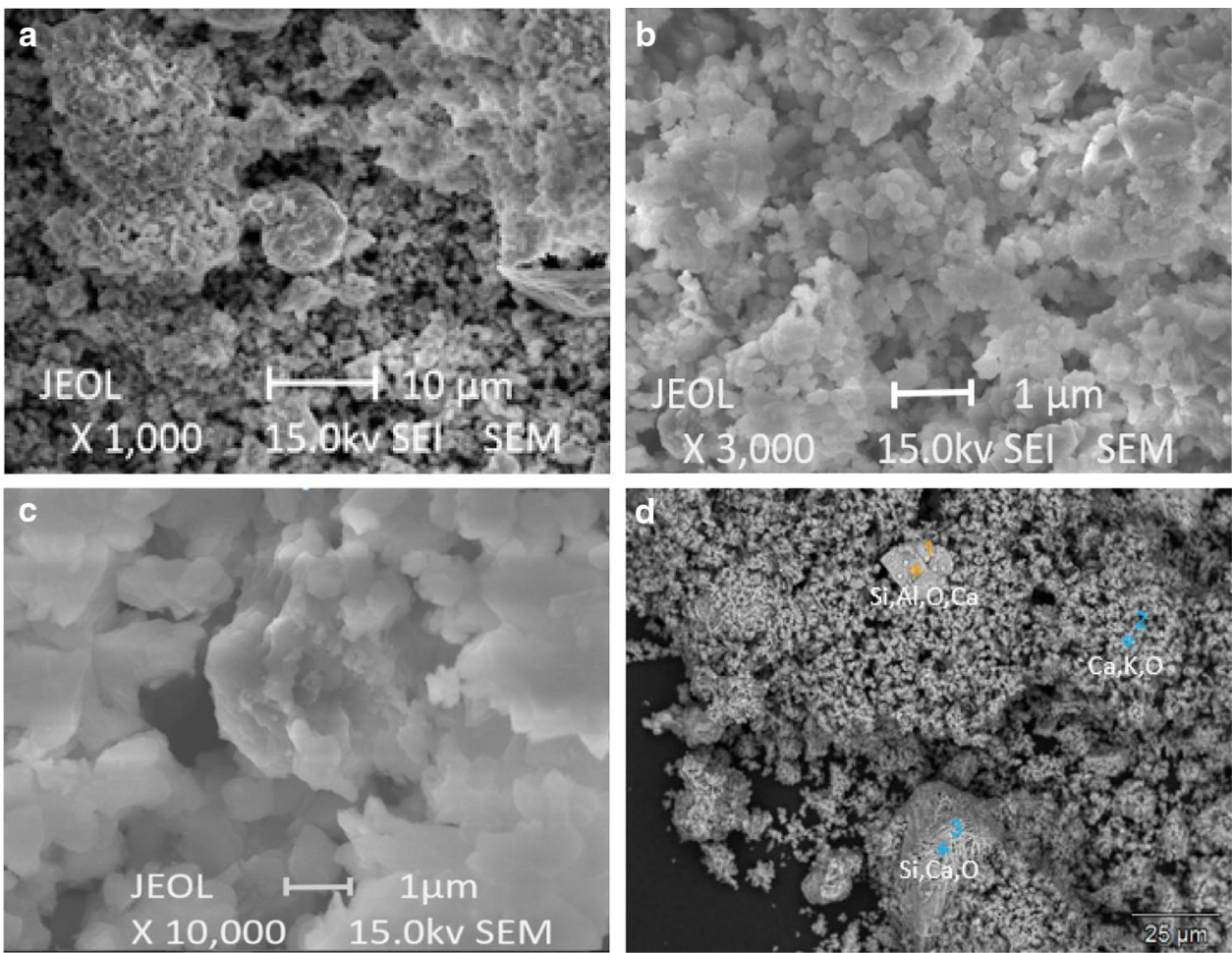

Table 1 Physicochemical properties of PCSO

\begin{tabular}{llc}
\hline Property & Unit & P. curatellifolia oil \\
\hline Oil content & $\%$ & 36.2 \\
Acid value & $\mathrm{mgKOH} / \mathrm{g}$ & 6.67 \\
lodine value & $\mathrm{gl}_{2} / 100 \mathrm{~g}$ & 82.62 \\
Saponification value & $\mathrm{mgKOH} / \mathrm{g}$ & 135.5 \\
FFA & $\mathrm{mgKOH} / \mathrm{g}$ & 3.33 \\
\hline
\end{tabular}

particle size, which could be the reason for exhibiting good performance during transesterification process [40].

\subsection{The physicochemical properties of PCSO}

The physicochemical properties of PCSO were determined as per AOCS Official Method CD1-25 [34] and AOCS Official Method CD3-25 [35] and the results summarized in Table 1. The oil content from P. curatellifolia seeds was found to be $36.2 \%$ which was suitably high for biodiesel production [1, 41, 42]. From the results shown in Table 1, the acid value was moderately high, suggesting high level of FFA that could cause soap formation. For oils with FFA greater than $1 \%$, it is advisable to use heterogeneous catalyst in order to avoid reduction of biodiesel yield arising from soap formation [43-45].

\subsection{Fuel properties of $P$. curatellifolia seeds oil fatty methyl ester (PCUME)}

The fuel properties of biodiesel produced from PCSO by transesterification reaction using calcined TIFSA catalyst were determined as per ASTM D6751 standard and results summarized in Table 2. It was observed that, viscosity, cloud and pour points, and acid value were within acceptable range as prescribed in ASTM D6751 while density was slightly higher than the limit. According to Ong et al. [46], density of biofuel depends on the chain length of methyl ester and its saturation level. The higher the unsaturation of methyl esters, the higher the density. Probably this could be the reason for the high density of PCUME. Denser fuels are less compressible and this results into poor atomization process and thus incomplete combustion $[4,42,46]$. The PCUME exhibited higher flash point temperature of about $172^{\circ} \mathrm{C}$. Flash point is the temperature at which the fuel starts to burn when it comes into contact with fire [47]. It is an important temperature from the safety point of view especially during storage and transportation [4]. The minimum allowable limit for pure biodiesel as per ASTM D6751 is $130^{\circ} \mathrm{C}$, therefore, PCUME meets the starndard. 
Table 2 Physical and chemical properties of produced Parinari curatellifolia biodiesel

\begin{tabular}{|c|c|c|c|c|c|}
\hline Property & Unit & Equipment used & $\begin{array}{l}\text { Petrol diesel } \\
\text { ASTM D975 limits }\end{array}$ & $\begin{array}{l}\text { Biodiesel ASTM D } \\
6751 \text { limits }\end{array}$ & $\begin{array}{l}\text { P. curatel- } \\
\text { lifolia methyl } \\
\text { ester }\end{array}$ \\
\hline Density @ $20^{\circ} \mathrm{C}$ & $\mathrm{Kg} / \mathrm{m}^{3}$ & Auton Paar density meter & 850 & $840-880$ & 889 \\
\hline Kinematic viscosity @ $40^{\circ} \mathrm{C}$ & $\mathrm{mm}^{2} / \mathrm{s}$ & Stabinger Viscometer & $2.0-4.5$ & $1.9-6.0$ & 5.8 \\
\hline Flash point & ${ }^{\circ} \mathrm{C}$ & Pensky-Martin & $60-80$ & 130 minimum & 172 \\
\hline Cloud point & ${ }^{\circ} \mathrm{C}$ & Test cabinet & -15 to -5 & -3 to 12 & 9 \\
\hline Pour point & ${ }^{\circ} \mathrm{C}$ & Test cabinet & -35 to -15 & -15 to 10 & -6.1 \\
\hline Calorific value & $\mathrm{MJ} / \mathrm{kg}$ & Bomb calorimeter & $42-46$ & - & 39.3 \\
\hline Acid value & $\mathrm{mgKOH} / \mathrm{g}$ & Titration apparatus & & $0.5 \max$ & 0.1 \\
\hline
\end{tabular}

\subsection{Catalyst performance and effect of different reaction parameters on biodiesel production}

\subsubsection{Influence of catalyst loading}

The performance of the calcined catalyst was evaluated by determining biodiesel yield, using Eq. (1), upon varying the reaction conditions: catalyst loading, temperature, reaction time, and methanol-to-oil ratio. The catalyst loading (calculated as wt\% of oil in our study) for a given reaction has great influence in determining the product yield. In testing catalyst loading effect, excess methanol-to-oil ratio of 12:1 was used since excess methanol tends to shift the reaction equilibrium towards the product side. The catalyst loading with respect to the weight of the oil was varied from 1 to $6 \%$ at intervals of $1 \%$ and the corresponding biodiesel yields were calculated using Eq. (1), while reaction time and temperature were maintained at $4 \mathrm{~h}$ and $60^{\circ} \mathrm{C}$, respectively, and stirring rate of $3000 \mathrm{rpm}$ was used for all the reactions. Figure 3 shows the influence of catalyst loading on biodiesel yield. When the amount of catalyst was increased from 1 to $5 \%$, the percent conversion and hence the biodiesel yield increased. Catalyst loading of $5 \mathrm{wt} \%$ to oil weight gave the highest yield of $95.7 \%$. The increase in yield with catalyst loading was probably due to the increase in surface area and the number of basic active sites for transesterification reaction. Upon increasing the catalyst loading above $5 \%$, biodiesel yield decreased dramatically. This was probably due to higher viscosity of reaction mixture resulting in poor diffusion and mass transport in the methanol-oil-catalyst system $[48,49]$. Therefore, $5 \%$ was found to be the optimal catalyst loading (Fig. 4).

\subsubsection{Influence of reaction time}

The yield of the methyl esters increases with reaction time [3] and the rate of conversion depends on how long the reaction takes place [18]. The optimum reaction time for biodiesel production using PCSO with $5 \%$ wt of catalyst

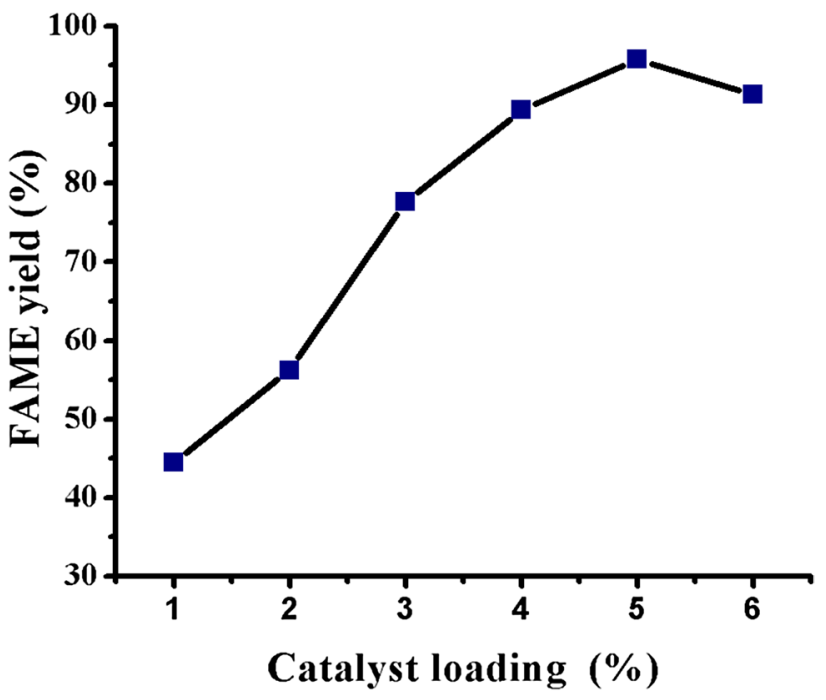

Fig. 4 Influence of catalyst loading on biodiesel yield

loading and excess methanol of 12:1 was determined by varying reaction time from 0.5 to $4 \mathrm{~h}$ at intervals of $30 \mathrm{~min}$ under same condition of temperature and agitation $\left(60^{\circ} \mathrm{C}\right.$ and $3000 \mathrm{rpm}$ ). The results for the effect of reaction time on the conversion of oil to biodiesel are presented in Fig. 5. The yield increased from $53.3 \%$ at $30 \mathrm{~min}$ to $96.2 \%$ at $120 \mathrm{~min}$ and remained almost constant up to $150 \mathrm{~min}$. Beyond 150 min reaction time, the yield decreased unceasingly albeit gradually. The decrease in biodiesel yield beyond $150 \mathrm{~min}$ was ascribed to the reversal of transesterification reaction that leads to loss of esters and formation of soap from fatty acids [50]. In this work, the optimal reaction time was therefore found to be $2 \mathrm{~h}$.

\subsubsection{Influence of methanol-to-oil molar ratio}

Methanol to oil molar ratio is also a critical parameter in the transformation of triglycerides to biodiedel. Transesterification reaction requires stoichiometric ratio of three 


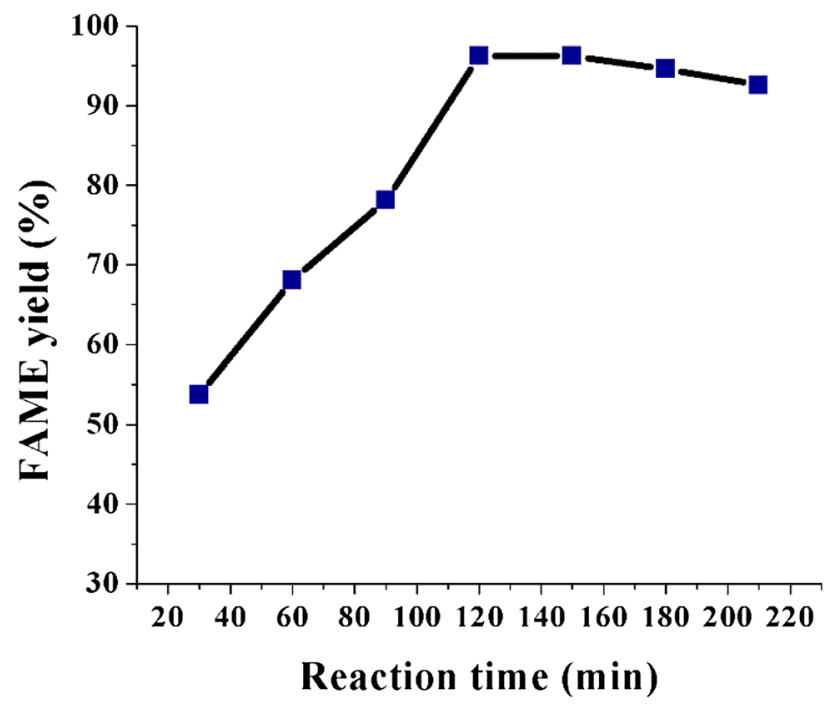

Fig. 5 Influence of reaction time on biodiesel yield

moles of methanol per mole of triglyceride. However, excess methanol improves the extent of the transesterification reaction biasing the equilibrium towards the product side $[37,48,51]$. In this work, the molar ratio of methanol to oil was varied from 3:1, 6:1, 9:1 to $12: 1$ and its influence on triglyceride conversion investigated using $5 \mathrm{wt} \%$ of catalyst, $2 \mathrm{~h}$ reaction time, $60^{\circ} \mathrm{C}$ reaction temperature, and $3000 \mathrm{rpm}$ stirring speed. It was observed that the yield increased as molar ratio increased. When 9:1 methanol to oil molar ratio was used, the highest biodiesel yield of 96.2 was obtained. No increase in yield was observed on increasing molar ratio to $12: 1$ as shown in Fig. 6, instead, a very small drop in the yield was observed. Too much alcohol, in our case methanol, has been shown

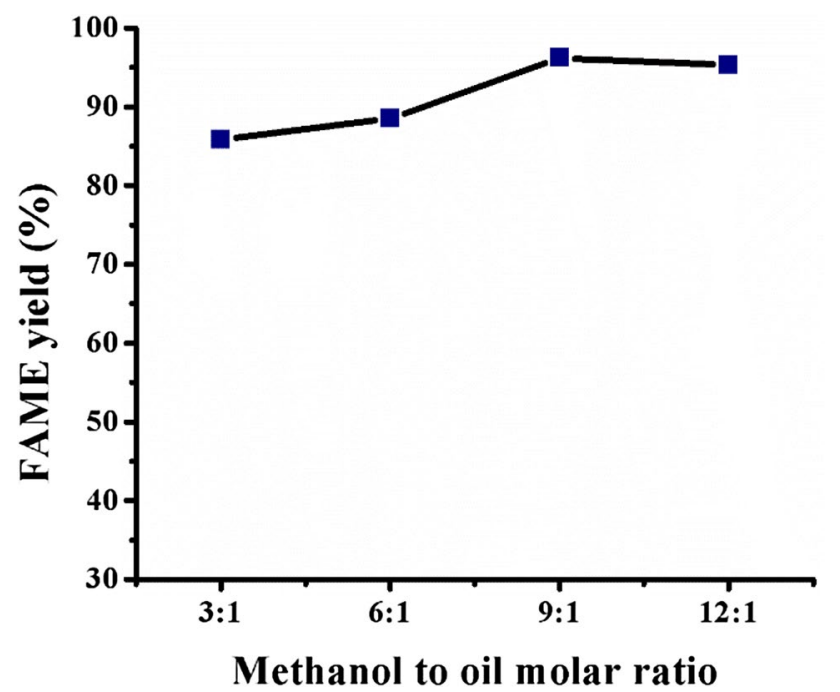

Fig. 6 Influence of methanol-to-oil molar ratio on biodiesel yield to increase the polarity of the reaction mixture resulting to increased solubility of glycerol in the methyl ester layer. This increases the likelihood of reverse reaction thereby reducing methyl ester (biodiesel) yield [52].

\subsection{Reusability of the catalyst}

The catalyst was reused four times in the transesterification process. In the first, second, third, and fourth run, the yields were $96.2,91.7,85.6$, and $74.2 \%$, respectively, under the optimal conditions of 1:9 methanol to oil molar ratio, $5 \mathrm{wt} \%$ catalyst loading, $2 \mathrm{~h}$ reaction time, $60^{\circ} \mathrm{C}$ reaction temperature, and $3000 \mathrm{rpm}$ stirring rate. The catalyst recyclability results in Fig. 7 show that catalyst efficiency based on biodiesel yield decreased in each subsequent run and this was caused by the deactivation of the catalyst. The deactivation was probably caused by poisoning of active site by water and $\mathrm{CO}_{2}$ from the air. The ability of the catalyst to be used several times shows that the catalyst has a huge potential in cutting operational expenses in biodiesel production associated with catalyst design and synthesis.

\subsection{Conclusion}

In this work, a low cost solid catalyst with superior activity and reusability was successfully synthesized by direct calcination of TIFSs (a waste agricultural biomass) for transesterification of PCSO. The calcination at $800^{\circ} \mathrm{C}$ afforded $\mathrm{CaO}$ catalyst with good catalytic activity, basic strength of 9.8, surface area of $378 \mathrm{~m}^{2} \mathrm{~g}^{-1}$, and pore diameter of $3.2 \mathrm{~nm}$. The best operating parameters for the production of biodiesel were found to $5 \mathrm{wt} \%$ catalyst loading, $2 \mathrm{~h}$ reaction

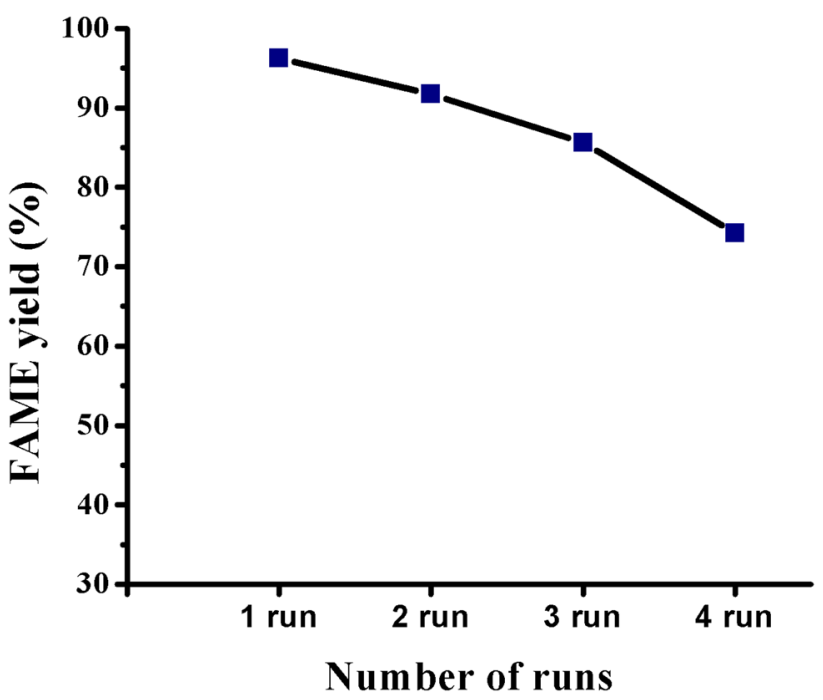

Fig. 7 Catalyst reusability versus \% FAME yield 
time, 9:1 methanol to oil molar ratio and $60^{\circ} \mathrm{C}$ reaction temperature. By using these optimum operating conditions, maximum yield of fatty acid methyl esters (FAME) of $96.2 \%$ was obtained. In addition, the key physico-chemical parameters of the biodiesel produced in our study, that is, viscosity, cloud point, pour point, and acid value were found to be within the acceptable standard limits stipulated by ASTM D6751. However, density and flash point were slightly higher than the limits. This shows that PSCO and the catalyst developed herein could be used to reduce the reliance on fossil diesel and thus help in mitigating climate change and reducing the national expenditure on fossil diesel imports. Moreover, the catalyst performance was not significantly reduced by reuse considering the biodiesel yield of $74 \%$ obtained in the fourth run. This does not only make the process of producing biodiesel cheap, but also translates to reduced amount of catalyst waste disposal thus making the catalyst environment friendly.

Acknowledgements Financial support from the National Institute of Transport is highly acknowledged. The authors also acknowledge direct and indirect support from the Nelson Mandela African Institution of Science and Technology (NM-AIST) and The World Academy of Sciences (TWAS).

\section{Compliance with ethical standards}

Conflict of interest We declare no conflict of interest in this work.

\section{References}

1. Atabani $A E$, Silitonga AS, Badruddin IA, Mahlia T, Masjuki $H$, Mekhilef S (2012) A comprehensive review on biodiesel as an alternative energy resource and its characteristics. Renew Sustain Energy Rev 16(4):2070-2093

2. Cantrell DG, Gillie LJ, Lee AF, Wilson K (2005) Structure-reactivity correlations in MgAl hydrotalcite catalysts for biodiesel synthesis. Appl Catal A 287(2):183-190

3. Wei Z, Xu C, Li B (2009) Application of waste eggshell as low-cost solid catalyst for biodiesel production. Bioresour Technol 100(11):2883-2885. https://doi.org/10.1016/j.biort ech.2008.12.039

4. Canakci M, Van Gerpen J (2001) Biodiesel production from oils and fats with high free fatty acids. Trans ASAE 44(6):1429

5. Chakraborty R, Bepari S, Banerjee A (2011) Application of calcined waste fish (Labeo rohita) scale as low-cost heterogeneous catalyst for biodiesel synthesis. Bioresour Technol 102(3):3610-3618

6. Helwani Z, Othman M, Aziz N, Fernando W, Kim J (2009) Technologies for production of biodiesel focusing on green catalytic techniques: a review. Fuel Process Technol 90(12):1502-1514

7. Ngamcharussrivichai $C$, Nunthasanti $P$, Tanachai S, Bunyakiat K (2010) Biodiesel production through transesterification over natural calciums. Fuel Process Technol 91(11):1409-1415

8. Naik SN, Goud VV, Rout PK, Dalai AK (2010) Production of first and second generation biofuels: a comprehensive review. Renew Sustain Energy Rev 14(2):578-597
9. Liu X, He H, Wang Y, Zhu S, Piao X (2008) Transesterification of soybean oil to biodiesel using $\mathrm{CaO}$ as a solid base catalyst. Fuel 87(2):216-221

10. Abdullah SHYS, Hanapi NHM, Azid A, Umar R, Juahir H, Khatoon $\mathrm{H}$, Endut A (2017) A review of biomass-derived heterogeneous catalyst for a sustainable biodiesel production. Renew Sustain Energy Rev 70:1040-1051. https://doi.org/10.1016/j. rser.2016.12.008

11. Marques Correia L, Cecilia JA, Rodríguez-Castellón E, Cavalcante CL, Vieira RS (2017) Relevance of the physicochemical properties of calcined quail eggshell $(\mathrm{CaO})$ as a catalyst for biodiesel production. Hindawi 2017:1-12

12. Mohan S (2015) Studies on optimization of biodiesel production-snail shell as eco-friendly catalyst by transesterification of neem oil. Int J Innov Res Technol Sci Eng (IJIRTSE) 1:5-10

13. Rezaei R, Mohadesi M, Moradi G (2013) Optimization of biodiesel production using waste mussel shell catalyst. Fuel 109:534-541

14. Obadiah A, Swaroopa GA, Kumar SV, Jeganathan KR, Ramasubbu A (2012) Biodiesel production from palm oil using calcined waste animal bone as catalyst. Bioresour Technol 116:512-516

15. Smith SM, Oopathum C, Weeramongkhonlert V, Smith CB, Chaveanghong S, Ketwong P, Boonyuen S (2013) Transesterification of soybean oil using bovine bone waste as new catalyst. Bioresour Technol 143:686-690

16. Sulaiman S, Ruslan NI (2017) A heterogeneous catalyst from a mixture of coconut waste and eggshells for biodiesel production. Energy Sources Part A Recov Util Environ Effects 39(2):154-159

17. Amos O, Ogunniyi DS, Odetoye TE (2016) Production of biodiesel from Parinari polyandra $B$. seed oil using bio-based catalysts. Niger J Technol Dev 13(1):26. https://doi.org/10.4314/njtd.v13i1 .5

18. Li C, Hu X, Feng W, Wu B, Wu K (2018) A supported solid base catalyst synthesized from green biomass ash for biodiesel production. Energy Sources Part A Recov Util Environ Effects 40(2):142-147

19. Jenkins B, Baxter L, Miles T Jr, Miles T (1998) Combustion properties of biomass. Fuel Process Technol 54(1-3):17-46

20. Vassilev SV, Baxter D, Andersen LK, Vassileva CG (2013) An overview of the composition and application of biomass ash. Part 1. Phase-mineral and chemical composition and classification. Fuel 105:40-76

21. Maneerung T, Kawi S, Wang C-H (2015) Biomass gasification bottom ash as a source of $\mathrm{CaO}$ catalyst for biodiesel production via transesterification of palm oil. Energy Convers Manag 92:234-243

22. Tang Z-E, Lim S, Pang Y-L, Ong H-C, Lee K-T (2018) Synthesis of biomass as heterogeneous catalyst for application in biodiesel production: state of the art and fundamental review. Renew Sustain Energy Rev 92:235-253. https://doi.org/10.1016/j. rser.2018.04.056

23. Sivasankar V, Rajkumar S, Murugesh S, Darchen A (2012) Tamarind (Tamarindus indica) fruit shell carbon: a calcium-rich promising adsorbent for fluoride removal from groundwater. J Hazard Mater 225:164-172

24. Meher B, Dash DK, Roy A (2014) A review on: phytochemistry, pharmacology and traditional uses of Tamarindus indica L. World J Pharm Pharm Sci 3(10):229-240

25. Wadekar M, Rode C, Bendale Y, Patil K, Gaikwad A, Prabhune A (2006) Effect of calcination cycles on the preparation of tin oxide based traditional drug: studies on its formation and characterization. J Pharm Biomed Anal 41(4):1473-1478

26. Ajayi IA, Oderinde RA, Kajogbola DO, Uponi JI (2006) Oil content and fatty acid composition of some underutilized legumes from Nigeria. Food Chem 99(1):115-120 
27. Zabeti M, Daud WMAW, Aroua MK (2009) Activity of solid catalysts for biodiesel production: a review. Fuel Process Technol 90(6):770-777

28. Oladimeji A, Bello M (2011) Proximate analysis and fatty-acid profiles of mobola plum seed. Elixir Appl Chem 41:5942-5943

29. Benhura $C$, Benhura $M$, Muchuweti $M$, Nyagura $S$, Gombiro $P$ (2012) Proximate analysis of Parinari curatellifolia fruit pulp of fruit from parts of Harare and a rural area in Zimbabwe. Pak J Nutr 11(7):541

30. Bazongo P, Bassole IHN, Nielsen S, Dicko MH, Shukla VK (2014) Studies in the evaluation of unconventional oils from burkina faso rich in linoleic acid, oleic acid or other unusual fatty acids. Food Process Technol

31. Hines DA, Eckman K (1993) Indigenous multipurpose trees of Tanzania: uses and economic benefits for people. FO:Misc93/9. Working paper. FAO, Rome, Italy

32. Taiwo O, Osinowo F (2001) Evaluation of various agro-wastes for traditional black soap production. Bioresour Technol 79(1):95-97

33. Lee D-W, Park Y-M, Lee K-Y (2009) Heterogeneous base catalysts for transesterification in biodiesel synthesis. Catal Surv Asia 13(2):63-77

34. Aoac (1993) Commercial fats and oils. American Oil Chemists Society (AOCS) Official Method CD1-25 for lodine Value. In: SC (ed). Assoc. Off. Anal. Chem, Washington

35. Aoac (1997) Section C: commercial fats and oils. American Oil Chemists Society (AOCS) Official Method CD3-25 for Saponification Value. Assoc. Off. Anal. Chem., Washington

36. Hui P, Meena S, Singh G, Agarawal R, Prakash S (2010) Synthesis of hydroxyapatite bio-ceramic powder by hydrothermal method. J Miner Mater Charact Eng 9(08):683

37. Lee AF, Bennett JA, Manayil JC, Wilson K (2014) Heterogeneous catalysis for sustainable biodiesel production via esterification and transesterification. Chem Soc Rev 43(22):7887-7916

38. Kouzu M, Kasuno T, Tajika M, Sugimoto Y, Yamanaka S, Hidaka J (2008) Calcium oxide as a solid base catalyst for transesterification of soybean oil and its application to biodiesel production. Fuel 87(12):2798-2806

39. Chavan SB, Kumbhar RR, Madhu D, Singh B, Sharma YC (2015) Synthesis of biodiesel from Jatropha curcas oil using waste eggshell and study of its fuel properties. RSC Adv 5(78):63596-63604

40. Viriya-Empikul N, Krasae P, Puttasawat B, Yoosuk B, Chollacoop N, Faungnawakij K (2010) Waste shells of mollusk and egg as biodiesel production catalysts. Bioresour Technol 101(10):3765-3767
41. Ahmad A, Yasin NM, Derek C, Lim J (2011) Microalgae as a sustainable energy source for biodiesel production: a review. Renew Sustain Energy Rev 15(1):584-593

42. Atabani A, Silitonga A, Ong H, Mahlia T, Masjuki H, Badruddin IA, Fayaz H (2013) Non-edible vegetable oils: a critical evaluation of oil extraction, fatty acid compositions, biodiesel production, characteristics, engine performance and emissions production. Renew Sustain Energy Rev 18:211-245

43. Marchetti JM, Miguel VU, Errazu AF (2007) Heterogeneous esterification of oil with high amount of free fatty acids. Fuel 86(5-6):906-910

44. Ramadhas AS, Jayaraj S, Muraleedharan C (2005) Biodiesel production from high FFA rubber seed oil. Fuel 84(4):335-340

45. Berchmans HJ, Hirata S (2008) Biodiesel production from crude Jatropha curcas $L$. seed oil with a high content of free fatty acids. Bioresour Technol 99(6):1716-1721

46. Ong $\mathrm{H}$, Silitonga $\mathrm{A}$, Masjuki $\mathrm{H}$, Mahlia $\mathrm{T}$, Chong W, Boosroh $\mathrm{M}$ (2013) Production and comparative fuel properties of biodiesel from non-edible oils: Jatropha curcas, Sterculia foetida and Ceiba pentandra. Energy Convers Manag 73:245-255

47. Ali Y, Hanna MA, Cuppett SL (1995) Fuel properties of tallow and soybean oil esters. J Am Oil Chem Soc 72(12):1557-1564

48. Kim H-J, Kang B-S, Kim M-J, Park YM, Kim D-K, Lee J-S, Lee K-Y (2004) Transesterification of vegetable oil to biodiesel using heterogeneous base catalyst. Catal Today 93:315-320

49. Lani NS, Ngadi N, Taib MR (2017) Parametric study on the transesterification reaction by using $\mathrm{CaO} /$ silica catalyst. Chem Eng Trans 56:601-606

50. Leung DY, Wu X, Leung M (2010) A review on biodiesel production using catalyzed transesterification. Appl Energy 87(4):1083-1095

51. Guo F, Peng Z-G, Dai J-Y, Xiu Z-L (2010) Calcined sodium silicate as solid base catalyst for biodiesel production. Fuel Process Technol 91(3):322-328

52. Issariyakul T, Dalai AK (2014) Biodiesel from vegetable oils. Renew Sustain Energy Rev 31:446-471

Publisher's Note Springer Nature remains neutral with regard to jurisdictional claims in published maps and institutional affiliations. 